\title{
LAS CARGAZONES DEL GALEÓN \\ DE LA CARRERA DE PONIEN'TE: \\ PRIMERA MITAD DEL SIGLO XVII *
}

\author{
OSTWALD SALES COLÍN \\ Universidad Autónoma Metropolitana \\ Iztapalopa, México
}

\section{RESUMEN}

El objetivo de este trabajo es discutir cómo la visión tradicional del comercio Acapulco-Manila, centrado en el envío, casi exclusivo, de plata con dirección a Filipinas, restringe el estudio del comercio exterior Nueva España-Asia, y desdeña al grupo de mercancías remitidas desde México a las islas de Poniente para subvenir las necesidades de la administración española. En ese sentido, el origen de las mercancías, la entrada y salida de barcos del puerto de Acapulco y los valores de los productos alistados para la gobernación insular permiten establecer una tipología de las cargazones del galeón.

\section{ABSTRACT}

The aim of his work is to discuss the traditional view of the Acapulco-Manila business, which so far has been exclusively centered on the silver trade. The significant merchandise trade has been neglected. In the paper we examine de volume and value of ships arriving and departing fron Acapulco, which allows us to have a better knowledge of the «galleon cargo".

* Una primera versión de este texto fue presentada dentro del ciclo de conferencias Galeones de la Plata. El comercio entre Filipinas y Nueva España, organizado por el Museo Franz Mayer (México, D. F., agosto de 1998), en el marco de la exposición del mismo nombre, y con motivo de los festejos del centenario de la República de Filipinas. Deseo agradecer las valiosas sugerencias de Jesús López, para mejorar este trabajo. 
Del trasvase de recursos novohispanos a Filipinas se pueden destacar tres, sin pretender que sean los más importantes ni los únicos. El primero se refiere a la migración Nueva España-Filipinas, en donde se ha logrado identificar a un importante contingente humano, en el cual figuraban: comerciantes, prelados novohispanos o peninsulares, autoridades del mismo origen, reos, acusados de diferentes delitos, tales como la vagancia, la homosexualidad, la bigamia, y los soldados, quienes conformaban el porcentaje más numeroso de individuos embarcados en el galeón. El segundo es, sin lugar a dudas, el aspecto más publicitado de las relaciones comerciales Acapulco-Manila, me refiero al envío de plata mexicana o peruana remitida en forma de situado, en reales de a ocho y como objetos artísticos, suntuarios o de culto religioso. El tercero alude al grupo de mercancías despachadas de «gobierno a gobierno», es decir, los artículos que el gobernador general de Filipinas y los oficiales reales de Manila solicitaban directamente al virrey de la Nueva España para sostener a la población civil, militar y religiosa avecindada en el archipiélago. Cada tópico ha sido estudiado por diferentes especialistas ${ }^{1}$, aunque, a mi juicio, el que se ha descuidado, mas no desdeñado, es el último, y sobre ello insistiré a lo largo de las próximas líneas.

En ese sentido, dentro del interés del aprovisionamiento del barco se inscribe el estudio sobre la composición de las cargas del galeón que viajaba de Acapulco a Manila. Por ello, mi contribución se divide en dos partes: primera, ofrecer un grupo de datos sólidos que permitan estudiar con mayor certeza estas cargas, sin llegar a establecer conclusiones perentorias; y segunda, aportar una tipología de las cargazones del galeón de la Carrera de las Islas de Poniente.

De entrada, es preciso subrayar los límites de este escrito: 1) se van a referir exclusivamente las cargas que alistadas en Nueva España, como peticiones por parte de los oficiales reales de Manila y del gobernador del archipiélago, viajaban a Filipinas ${ }^{2}$; 2) hay que tener en cuenta que el tema se analizará desde una perspectiva mexicana, concretada en lo referente a la preocupación por parte de las autoridades novohispanas en continuar con Filipinas, en medio de la guerra hispano-holandesa; 3) en lo que se refiere al tiempo se va a insistir sobre la primera mitad del

${ }^{1}$ Bauzon (1981); García de los Arcos (1989), pp. 231-241; García de los Arcos (1996); Muro (1970), pp. 466-491; Valdés Lakowsky (1987) y Yuste López (1984).

2 Durante la época colonial, la forma común de referir a las Filipinas era con el nombre de Islas de Poniente, por ello refiero las cargazones del galeón de la Carrera de Poniente. 
siglo XVII, especialmente durante los años 1626 a 1654, pues son los que abarca la documentación empleada.

Hablar de la historiografía del comercio transpacífico es referirse a un campo demasiado vasto, como para ser abordado en este espacio aunque sea compendiadamente. Éste no es mi propósito. Por ello, he recurrido a los excelentes estados de la cuestión de P. Pérez Herrero y M. F. García ${ }^{3}$, que condensan una importante información, proponiendo nuevos cauces investigativos. Tratando estos dos escritos, ambos autores acuerdan que, tradicionalmente, se ha establecido dentro del comercio transpacífico una visión desde la óptica de Filipinas como ramal de este importante negocio, cuestión suficientemente comprobada. No obstante, se limita el comercio América-Asia al envío de plata como la mercancía de mayor demanda. El hecho es que la plata constituyó el principal objeto de exportación novohispana a Filipinas. Sin embargo, creo que hay un obstáculo en esta visión restringida desde el punto de vista del comercio exterior de Nueva España con Asia, lo cual se imbrica, necesariamente, al gasto de Estado para mantener la presencia española en Insulindia, me refiero, especialmente, a los géneros enviados de «gobierno a gobierno».

¿Qué sabemos de la composición de las cargas del galeón de Manila que llegaban a América procedentes de Filipinas? Mucho y poco. Mucho, porque $\mathrm{C}$. Yuste cuenta con una frondosa producción académica, que con suma prudencia podría generalizar grosso modo la presencia de productos suntuarios, textiles y especias en Nueva España ${ }^{4}$, a esta lista se añade W. L. Schurz, quien junto con V. González Claverán sostienen la llegada de esclavos asiáticos a América. Poco, debido a que todavía no se tienen cifras concretas para cuantificar este intercambio, a excepción del trabajo de M. L. Díaz-Trechuelo que analiza en detalle el comercio chino-filipino de los años 1660-1679'.

El comercio en sentido opuesto, es decir, lo exportado de Nueva España para subvenir las carencias de la administración española avecindada en Filipinas, apenas ha sido bosquejado tímidamente. C. Yuste propone una tipología de siete productos (plata, grana cochinilla, jabón, sombreros, vino, hilo de Campeche y artículos de herrería) enviados de «gobierno a gobier-

${ }^{3}$ García de los Arcos (1997), pp. 165-180, y Pérez Herrero (1989), pp. 445-457.

4 Yuste López (1984); Yuste López (1987), pp. 189-217; Yuste López (1991); Yuste López (1992), pp. 91-111; Yuste López (1993), pp. 211-224, y Yuste López (1995), pp. 231-264.

5 Diaz-Trechuelo (1980), pp. 134-148; Schurz (1939), p. 32, y González Claverán (1989), pp. 523-532. 
no», no obstante abarca un período muy amplio que, sin la crítica pertinente, podría transformarse en una terrible generalización, ya que aborda los años 1590-1785. Frente a esta limitante, es necesario la construcción de una tipología nueva que responda a los diferentes períodos de la presencia hispana en Filipinas. Obviamente, en casi doscientos años debió haber existido alguna variación. L. Bauzon, por su parte, sólo se limita a enlistar una serie de productos, tanto de origen mexicano como europeo, remitidos a Manila (balas, papel, plumas, vino) sin realizar un análisis más amplio. M. F. García apunta que «el resto de los productos no ha sido estudiado, aunque sí mencionado, como el salitre, el plomo, el hierro, las medicinas, el vino, los naipes, el papel de Castilla, etcétera». En efecto, es preciso añadir que en 1994 publiqué un breve artículo titulado «Las cargas del galeón de Manila», en donde la visión se restringía, precisamente, a la cita de algunos efectos exportados de Nueva España a Filipinas, ya que tampoco se apuntaban cifras concretas. A. M. Prieto Lucena refiere «géneros habituales» para indicar las cargazones de Acapulco a Manila, sin embargo no define esa categoría analítica, ni la composición de las cargas. Finalmente, R. Widmer sólo comenta el origen novohispano de algunos víveres consumidos por la tripulación del barco en su viaje de retorno a Manila ${ }^{6}$.

\section{TIPOLOGÍA DE LAS CARGAS DEL GALEÓN}

\section{A) Las fuentes}

La primera cuestión aclaratoria se refiere a la fecha 1626-1654. Con esto quiero apuntar las limitantes de la documentación, cuyos años son, evidentemente, arbitrarios, pues cubren básicamente ese período. Pero si se escoge 1626-1654 existe la posibilidad de indicar algunas de las manifestaciones abiertas de la conflictividad imperial, tales como la visita de Pedro de Quiroga en el puerto de Acapulco (1635), como reacción inmediata por parte de los cargadores de las flotas de Indias, frente a los excesos cometidos en el comercio transpacífico; la polémica temprana de libre comercio (1644) entre Filipinas, Nueva España y Perú, cuyo punto focal insistía en la posibilidad de reabrir el contacto Acapulco-Callao, cortado

${ }^{6}$ Bauzon (1981), p. 88; García de los Arcos (1997), pp. 178 y 179; Prieto Lucena (1984), p. 44; Sales Colín (1994), pp. 30-34; Widmer (1990), pp. 107 y 108, y Yuste López (1984), p. 26. 
indefinidamente desde 1634; y el estentóreo descalabro en las comunicaciones náuticas mexicano-filipinas de 1646 a 1648, cuando en dos años seguidos la navegación se interrumpió por varias razones, una de ellas fue la guerra hispano-holandesa librada en el archipiélago. Incluso es un período álgido en la historia interna de las islas, ya que se conjugaron incidentes de toda índole: levantamientos chinos, sublevaciones indígenas, el endémico conflicto hispano-mahometano del sur del archipiélago, la llegada irregular de situados, incendios y terremotos ${ }^{7}$.

Otra deficiencia insoslayable radica en que por el momento no poseo información relativa al jabón, grana cochinilla y naipes remitidos de Nueva España a Filipinas, por lo tanto, la tipología que ofrezco merece el carácter de tentativa. En suma, las fuentes manejadas de ninguna manera permiten establecer series de mercancías, de precios, de proveedores y de barcos; no obstante, los datos son valiosos por lo que aportan. Con todas estas salvedades, la información cuantitativa se divide en tres partes: las memorias de los oficiales reales de Manila y del gobernador general del archipiélago enviadas al virrey de la Nueva España, los índices reales correspondientes a los despachos de los barcos del puerto de Acapulco a Filipinas, y los testimonios del remate de los productos vendidos en Puebla, la ciudad de México y el puerto de Acapulco.

En los memoriales del gobernador se solicitan víveres para la administración española insular, armas para la guerra hispano-holandesa librada en el Sudeste de Asia, e inclusive algunos pertrechos para la construcción de barcos en Cavite, asimismo especifica color, tamaño, cantidad, volúmenes, piezas y el lugar de donde deben proceder las mercancías; los índices reales correspondientes al despacho de las naos de México a Filipinas consignan el nombre del proveedor, de la mercancía, la cantidad, el origen del producto y, en pocas ocasiones, el valor; en los remates y los testimonios de las mercaderías se apunta el nombre y origen del proveedor, así como el nombre, la cantidad, el valor y la calidad del artículo; finalmente los mandamientos para el pago de los efectos vendidos para aprovisionar el barco, el puerto y para alimentar a los sirvientes de Acapulco también arrojan datos interesantes en lo referente a la entrada y salida de barcos, con los cuales he podido realizar mi propuesta para tipificar las cargazones del galeón. En efecto, la información sólo aduce a los efectos y los víveres alistados y comprados en la ciudad de México, Puebla, Veracruz y Acapulco, así como los originarios de Europa, reexportados a Filipinas.

${ }^{7}$ Díaz-Trechuelo (1984), pp. 129-152; García de los Arcos (1993), pp. 39-67; Sales Colín (1997a), pp. 91-119, y Sales Colín (1997b), pp. 127-146. 


\section{B) Los barcos}

Una parte indisolublemente ligada a las cargas del galeón es lo relacionado con los barcos. ¿Cuántos realizaron el viaje transpacífico durante los doscientos cincuenta años de la fructífera e intensa relación mexicano-filipina? La respuesta rebasa con creces los alcances de este somero análisis. No puedo asegurarlo contundentemente, pero creo que aún se desconoce. No obstante, se cuenta con tres importantes acercamientos referentes a la entrada y salida de naves filipinas del puerto de Acapulco para el siglo Xvi, entre los años 1591-1663 ${ }^{8}$.

El primero de ellos es el «Movimiento anual unitario del puerto (entradas y salidas) de 1591 a $1622 »$, elaborado por $P$. Chaunu, quien se apoyó en las cuentas de almojarifazgo de la caja de Acapulco del Archivo General de Indias (AGI). De los treinta y dos años que analiza, sólo en doce ofrece información relativa a los navios procedentes de Filipinas, cuyo número es de 23. El segundo se titula «Entrada de barcos en el puerto de Acapulco. 1626-1654», construido por O. Sales Colín en base a la información de los fondos Archivo Histórico de Hacienda, Reales Cédulas Originales y Duplicados, y General de Parte del AGN. Sin embargo, la deficiencia más acentuada es el socavón de ocho años que va de 1627 a 1634, pues se desconoce el número de barcos originarios de Filipinas. De los veintinueve años que se intentan analizar, solamente se cuenta con datos para catorce, lo que arroja un total de 19 galeones originarios de Asia. El tercero lleva por nombre «Movimiento de los navios que mantuvieron contacto entre Nueva España y Filipinas en la década estudiada (1653-1663)», dicho cuadro fue realizado por A. M. Prieto Lucena empleando la documentación de los fondos Audiencia de Filipinas y Escribanía de Cámara del AGI. De los once años analizados, sólo carece de información para $1657^{\circ}$. El resultado final es de 16 barcos. En suma, una primer cifra de los galeones que realizaban el contacto Nueva España-Filipinas entre los años 1591-1663 sería de 57. Con todo, esta aproximación aún deberá criticarse, compararse y revisarse, lo cual permitirá tener mayor certeza sobre el nexo de todo tipo de comunicaciones entre Europa-Nueva España-Asia: los galeones.

${ }^{8}$ Espero que no se considere como un gesto de vanidad el trabajo citado con mi nombre. Más bien, ahora tengo la oportunidad de autocriticarme.

${ }^{9}$ Chaunu (1976), pp. 218-227; Prieto Lucena (1984), p. 44, y Sales Colín (1996), pp. 97-119. Hay que restarle a Sales Colín el barco San Diego de 1654, puesto que P. Lucena ha registrado el mismo navío, por lo tanto Sales Colín sólo tendría 18 bajeles apuntados. 
Con los «barcos» se robustecen varias cuestiones (ver apéndice I, p. 649). Se ha podido comprobar que no obstante la inexistencia del nombre de los galeones, en la documentación consultada, se remitían las mercancías solicitadas por la gobernación insular, por ejemplo, así sucede durante los años 1628, 1633, 1634 y 1644 (ver apéndice II, p. 650), lo cual saca a luz que, pese a la terrible inundación sufrida por la ciudad de México de 1629 a 1634, no se suspendió el trajín de las mercancías desde la capital hasta la sede americana del tráfico asiático. Por otro lado, la visita de Pedro de Quiroga en el puerto de Acapulco durante los años de 1635 a 1639 agudizó la inspección fiscal, aunque no se prohibió la salida de galeones rumbo a la colonia asiática, ni la entrada de barcos provenientes de Manila. Así pues, la coyuntura de estos años confirma que las islas dependen del tráfico comercial con Nueva España, pues estaban sumergidas en un período de constante actividad militar, y se necesitaba pólvora para librar los combates. Por ello, Sebastián Hurtado de Corcuera, gobernador de Filipinas, abogaba por la importación de salitre peruano y mexicano, que tenía un bajo costo, pues los holandeses obstaculizaban la llegada de esa materia prima originaria de la India, tan imprescindible para la fabricación de la pólvora ${ }^{10}$. Finalmente, lo relativo al descalabro náutico de 1646 a 1648 es fundamental, pues he constatado que durante esos años no llegaron barcos procedentes de Filipinas a Nueva España, ni zarparon galeones de Acapulco con dirección al archipiélago, lo que originó un corte temporal en las comunicaciones transpacíficas, así como la interrupción del envío de productos solicitados por el gobernador general, dando paso a la compra ilícita de municiones, armas, salitre y fierro a comerciantes ingleses y daneses ${ }^{11}$. En efecto, la guerra hispano-holandesa obligaba a satisfacer, perentoriamente, las necesidades de pertrechos militares cuando no llegaban los originarios de Nueva España.

\section{C) Las mercancías}

Es preciso subrayar que mediante el análisis de las «mercancías» ha podido establecerse que los cargamentos de estas embarcaciones tienen un doble origen: mexicano y extranjero, a fin de tocar el punto de los productos fabricados y elaborados en Nueva España y Europa ligados al comercio internacional transpacífico

${ }^{10}$ Sales Colín (1997b), 127-146.

"Sales Colín (1997a), 91-119. 
Productos europeos. Entre los víveres europeos están todos los originarios de Castilla, tales como el vino, harina de trigo, aceite y vinagre blanco. Mientras que los pertrechos más corrientes eran el hilo galladero, también de Castilla. Fue hasta 1677 cuando Adrián Roo y Baltasar Kiel hicieron una propuesta para fundar una factoría de jarcia en Galicia. Pero en España no funcionaban industrias especializadas en la manufactura de tela para velamen y, durante la segunda mitad del siglo XvII, los galeones de la Carrera de Indias eran aprestados con velas que procedían de los Países Bajos. En efecto, el velamen estaba monopolizado por los «neerlandeses» ${ }^{12}$. Aunque la lona enviada a las islas procedía de Castilla, pues se compraba en aquel lugar, sin embargo aún falta indagar si también era de origen holandés a pesar de la guerra de Treinta Años. En la Nueva España se embarcaba lona lavada remitida al real campo de Manila o puerto de Cavite para los nuevos galeones, mientras que la lona cortada era estibada para el uso del bajel durante la travesía ${ }^{13}$. Las espadas con sus dagas, guarniciones, pomos, brocales y conteras procedían de Alemania, Francia y Génova, las cuales eran de dos clases: de cuatro puentes y de seis puentes ${ }^{14}$. De Génova también se importaba el papel blanco en resma, con el cual se manufacturaban los libros de 300 ó 400 fojas ${ }^{15}$ «con su cubitaje de tabla además de estar forrados y encuadernados en cordobán con cordones de seda enlazados», para la caja y contaduría de Filipinas. Los arcabuces y los mosquetes de cuerda con sus frascos y frasquillos eran originarios de Vizcaya, al igual que parte de la herrería y los estoperoles.

Productos novobispanos. Entre los víveres que recurrentemente se enviaban a Filipinas destaca el sebo blanco de cerdo, producido en Puebla, porque «se hallare con más comodidad en los Ángeles de donde se suele enviar para mayor ahorro de la real hacienda» ${ }^{16}$. Asimismo, de ahí pro-

12 Serrano Mangas (1985), pp. 147, 148, 163 y 164.

${ }_{13}$ Ver nota 42.

${ }^{14}$ AGN, AHH, 6, exp. 206, «Índices reales de títulos correspondientes al despacho de la nao en 1634», México. AGN, AHH, 6, exp. 266, «Índice de reales títulos correspondientes al despacho de la nao de 1639», México, 1639. AGN, AHH, 6, exp. 327, «El valor de 600 espadas con sus dagas para Filipinas», México, 25-2-1640.

${ }^{15}$ AGN, AHH, 6, exp. 206, «Índices de reales títulos correspondientes al despacho de las naos de 1634», México, 1634. AGN, AHH, 6, exp. 494, «Remate de 4 libros de papel de marca mayor para Filipinas», México, 16-3-1636. AGN, AHH, 6, exp. 366, «Remate de papel en resma para Filipinas», México, 26-3-1636. AGN, AHH, 6, exp. 56, «El valor de los libros de papel de marca mayor para el gobernador de las Islas», México, 16-2-1641.

${ }^{16} \mathrm{AGN}, \mathrm{AHH}, 6$, exp. 432, «El valor del sebo para Filipinas», México, 28-3-1628. AGN, AHH, 6, exp. 62, «Recaudos para la paga de los efectos que entregó el alcalde mayor de la Puebla», Puebla, 3-1-1634. 
cedían las leguminosas como el garbanzo, frijol, lenteja, haba, los alimentos de la «dieta seca», las frutas, las legumbres, y el queso de «leche de cabra y oveja revueltos» ${ }^{17}$. La pasa de almonillar ( $\dot{\text { ? }}$ ) y la almendra del condado (¿) también eran de origen mexicano. La panificación en gran escala se concentraba en Puebla, ahí se preparaba la galleta de mar para el apresto del puerto de Acapulco y de la nao que retornaría a Filipinas. En cuanto a calidades sobresalían dos tipos: el pan bazo, de color moreno que tira a amarillo; y el pan blanco, elaborado con harina más refinada. Asimismo, se fabricaba el bizcocho que se conduciría a Veracruz para las embarcaciones de la Armada de Barlovento y los galeones de la Carrera de Indias en su retorno a Sevilla ${ }^{18}$.

Tres tipos de carne salada eran embarcados en la nave para consumirse durante la travesía a Filipinas: pescado, tocino y jamón. El tocino y el jamón procedían de Puebla ${ }^{19}$. La pesca practicada en las costas de Acapulco y de Igualapa proporcionaba el pescado, que después pasaba por el proceso de salazón en el puerto, para asegurar las dietas de la tripulación ${ }^{20}$.

En cuanto a los pertrechos, el cáñamo para la jarcia procedía, posiblemente, de la sabana guerrerense, producido en la cordonería del puerto localizada hacia los cerros. De acuerdo con R. Widmer, V. González Claverán y mi propia búsqueda de archivo, se sabe que la brea transportada en petates se traía a lomo de indios desde Citlaltomagua, Suchitepec, Ecatepec, Ejutla ${ }^{21}$ y del puerto de Huatulco ${ }^{22}$. Acapulco también era especialmente rico en recursos forestales, el cerro de La Brea, cercano al puerto,

17 AGN, AHH, 6, exp. 433, «Quesos para Filipinas», México, 2-4-1628. AGN, AHH, 472, exp. 61, «Diversos géneros que se entregan en el puerto de Acapulco para las naos de Filipinas», Acapulco, 1644 y 1645.

${ }_{18}$ AGN, AHH, 6, exp. 554, «Bizcocho para la nao de Filipinas, Veracruz y la flota de Barlovento», México, 1653. AGN, AHH, 472, exp. 61, «Diversos géneros que se entregan en el puerto de Acapulco», Acapulco, 1-4-1645.

${ }_{19} \mathrm{AGN}, \mathrm{AHH}, 6$, exp. 328, «El valor de 250 arrobas de tocino para el despacho de las naos», México, 23-2-1640. AGN, AHH, 6, exp. 342, «El valor de 450 arrobas de tocino para las naos de Filipinas», México, 1639. AGN, AHH, 6, exp. 62, «El valor de 500 arrobas de tocino de México para las naos de Acapulco que han de viajar a Filipinas», México, 10-1-1637. AGN, AHH, 6, exp. 311, «El valor de 450 arrobas de tocino para aprestar las naos de Filipinas», México, 1639.

${ }^{20}$ Widmer (1990), p. 133. AGN, AHH, 6, exp. 552, «Lo que se debe de pescado salado», Acapulco, 22-3-1628, AGN, AHH, 600, exp. 223, «Mandamiento para la paga de pescado seco salado para las naos de Filipinas», Acapulco, 21-3.1653. AGN, AHH, 6 , exp. 206, «Índices de reales títulos correspondientes al despacho de la nao de Filipinas en 1634», México, 1634.

${ }^{21}$ Widmer (1990), p. 107.

${ }^{22}$ AGN, AHH, 6, exp. 412, «Navío que se detuvo en el puerto de Acapulco entendido sería necesario para Filipinas», México, 6-12-1616. 
estaba poblado por pinos de donde se extraía esa materia prima. Inclusive, durante la visita de Alejandro Malaspina en el siglo xviI, media legua de ese bosque llegó a cotizarse en 700 pesos ${ }^{23}$.

Las hojas de lata, los aros de fierro, las prisiones (grilletes y cadenas) «para los forzados de las Islas» ${ }^{24}$ que trabajaban en las galeras, la «pólvora grasosa», el «salitre refino» y el plomo eran mexicanos. Por ejemplo, el plomo puede clasificarse en tres tipos: plomo en pan extraído de las minas de Ixmiquilpan, plomo en pan de San Luis y plomo tirado de Ixmiquilpan ${ }^{25}$. Los achiotes de cera se fabricaban en Campeche y también se importaban de China ${ }^{26}$. El salitre enviado a Poniente, La Florida, la guerra contra los Chichimecas y la Nueva Galicia era, en parte, extraído de las minas de Iztapalapa ${ }^{27}$. Sin embargo, no hay certeza de que toda esta materia prima procediera del mismo lugar. Por otra parte, Widmer anota que los maderos necesarios en Acapulco procedían de los bosques de la sierra, flotados sobre el río Papagayo, la demanda se complementó con la explotación de maderas como los manglares, caobas, ceibas y cedros de la costa, además la tablazón de pino ordinaria también se transportaba desde la ciudad de México y Tixtla ${ }^{28}$ hasta Acapulco. En lo referente a los cajones

${ }^{23}$ González Claverán (1993), p. 180. AGN, GP, 7, exp. 503, foja 334, «Para que el alcalde mayor del puerto de Acapulco informe acerca de lo que pide Alonso de Valderrama. Se dé licencia para hacer brea en aquel distrito», México, 1-2-1633.

${ }^{24} \mathrm{AGN}, \mathrm{AHH}, 6$, exp. 103, «Indices reales correspondientes al despacho de la nao a Filipinas en 1641», México, 1641.

${ }^{25} \mathrm{AGN}, \mathrm{AHH}, 6$, exp. 408, «El valor de tablas y plomo en pan para las naos de Filipinas», México, 27-1-1627. AGN, AHH, 6, exp. 415, «El valor del plomo tirado que se remató para Filipinas», México, 3-4-1629. AGN, AHH, 6, exp. 206, «Índices de reales títulos correspondientes al despacho de las naos a Filipinas correspondientes al año de 1634», México, 1634. AGN, AHH, 6, exp. 39, «El valor de los géneros de lata que se remataron en la almoneda para Filipinas», México, 28-3-1636. AGN, AHH, 6, exp. 310, «Testimonio del remate de plomo tirado para Filipinas», México, 31-3-1639. AGN, AHH, 6, exp. 307, «El valor de 200 quintales de plomo tirado para Filipinas», México, 11-3-1640. AGN, AHH, 6, exp. 103, «Índices de reales títulos correspondientes al despacho de las naos a Filipinas del año 1641», México, 1641. El plomo remitido a Filipinas era de dos tipos: el plomo en pan y el plomo tirado. De acuerdo con la documentación examinada, destacando naturalmente su fragmentación, la media de plomo remisionada a las Islas fue de 200 quintales anuales.

${ }^{26} \mathrm{AGN}, \mathrm{AHH}, 6$, exp. 329, «El valor de 150 achiotes de cera blanca de Campeche para Filipinas», México, 27-2-1640. AGN, AHH, 6, exp. 415, «El valor de 250 achiotes de cera para Filipinas», México, 30-4-1629.

${ }^{27}$ AGN, GP, 3, exp. 10, foja 5, «Personas que trabajan en las minas de salitre», México, 16-1-1587.

${ }^{28}$ Widmer (1990), p. 107. AGN, AHH, 6, exp. 207, «El valor de las tablas de pino que se dieron en Acapulco», Acapulco, 1626. AGN, AHH, 6, exp. 408, «El valor de las tablas y plomo en pan para las naos de Filipinas», México, 27-1-1627. AGN, AHH, 6, 
«enlacados y enclavados», para guardar el sebo de cerdo, y las pipas abatidas «con diez aros de fierro, diez fondos y veinticuatro duelas», algunas destinadas para envasar el vino, se fabricaban en Puebla, la ciudad de México y Acapulco ${ }^{29}$.

Entre los textiles, el paño embarcado se dividía en dos clases: catorceno, común (negro), mezcla y de colores; y diez y ocheno, de siete cuartas de ancho y 1.800 hilos azules, manufacturados en los obrajes de Puebla y la capital virreinal. Los sombreros que tanta demanda tenían entre los mercaderes «manilos» y la administración española insular eran de los llamados valones: finos y entrefinos, que estaban «tejidos en México, cairelados con sus toquillos de toca de lino, teñidos en esta ciudad». También desde la ciudad de Los Ángeles se transportaban las jerguetas «de todos colores para remitir a las Islas». Finalmente, los sayales pardos y las frazadas de Tlaxcala «han de ser mexicanas conforme a la muestra» ${ }^{30}$.

En síntesis, no debe exagerarse la importancia de todos los pertrechos y víveres aviados de México a Filipinas, porque constituyeron una parte relativamente pequeña dentro de las cargazones del galeón de la carrera de Poniente. No cabe duda, el archipiélago representaba un mercado seguro, pues todos los años, desde México, se enviaban remesas de diferentes productos. Es cierto, empero, que eran un monto reducido enviado de «gobierno a gobierno», sin embargo es posible conocer detalladamente los flujos comerciales convergentes en Nueva España que nutrían los cargamentos de estos galeones. Uno de ellos es el originario de Europa con ramificaciones en Francia, Alemania, Génova y España; y el otro se localiza

exp. 315, «El valor de 1.100 tablas de pino para las naos de Filipinas», Acapulco, 29-4-1639. AGN, AHH, 6, exp. 398, «Lo que se libró por el valor de 500 tablas de pino», Acapulco, 20-10-1635.

${ }^{29}$ AGN, AHH, 6, exp. 336 «Testimonio del remate de pipas», México, 5-1-1637. AGN, AHH, 6, exp. 434, «Pipas abatidas para Filipinas», México, 1628. AGN, AHH, 6, exp. 198, «Mandamiento para que a cada tonelero se le socorra con 100 pesos adelantados», Acapulco, 27-2-1635. AGN, AHH, 6, exp. 376, «El valor de 257 pipas que se remataron y aderezaron en el puerto de Acapulcom, Acapulco, 3-1-1639.

${ }^{30} \mathrm{AGN}, \mathrm{AHH}, 6$, exp. 42, «El valor de 4.000 varas de paño para Filipinas», México, 13-2-1635. AGN, AHH, 6, exp. 202, «El valor de 1.998 varas de paño para Filipinas», México, 1636. AGN, AHH, 6, exp. 556, «Paños que se remataron para Filipinas», México, 12-3-1627. AGN, AHH, 6, exp. 431, «El valor de 3.000 frazadas para Manila», México, 6-4-1628. AGN, AHH, 6, exp. 403, «El remate de 12.000 jerguetas para Filipinas», México, 31-1-1629. AGN, AHH, 6, exp. 428, «Remate de fieltros para sombreros para Filipinas», México, 30-3-1628. AGN, AHH, 6, exp. 403, «Remate de fieltros de sombreros para Filipinas», México, 9-3-1629. AGN, AHH, 6, exp. 44, «Remate de sombreros valones para Filipinas», México, 29-11-1629. AGN, AHH, 6, exp. 62, «Recaudos para la paga de los efectos que entregó el alcalde mayor de la Puebla», Puebla, 3-1-1654. 
en el interior del virreinato novohispano con sus ramales en la ciudad de México, Puebla, Tlaxcala, Acapulco y Veracruz. Así pues, la razón esgrimida por la Corona para comprar allí los productos radicaba en su bajo precio ${ }^{31}$. Inclusive, en las postrimerías del siglo XVII, en 1697, se reporta que los «géneros, pertrechos y bastimentos se remiten de Vera Cruz, Puebla y México» ${ }^{32}$.

El origen de los productos y las cifras anotadas en el apéndice I podrían ayudar a comprender lo que $\mathrm{R}$. Romano llama «la capacidad de absorción del mundo hispanoamericano» ${ }^{33}$. En efecto, el imperio de América muestra

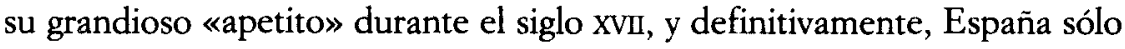
satisfacía parcialmente las necesidades de la administración hispana instalada en Filipinas, ya que de Castilla procedía vino, vinagre, aceite, harina y lona. En ese sentido, es fácil advertir la geografía novohispana de la producción local artesanal cuando se habla de tejidos de Puebla y Tlaxcala; la geografía agrícola del trigo poblano, y ganadera con el tocino y jamón de la ciudad de México y Los Ángeles; y la geografía minera del plomo de Ixmiquilpan (Hidalgo) y San Luis (San Luis Potosí). Así pues, creo que no es una casualidad, sino un efecto reforzador de las relaciones comerciales novohispanas en el plano interregional, todo lo anterior es apenas un modesto indicador que engrosa la idea de que «la América española no presenta ninguna señal de crisis en el siglo XVI» ${ }^{34}$. Una prueba contundente se refiere al origen de las mercancías embarcadas en el galeón de Acapulco despachadas a la gobernación de Filipinas, 80 por 100 eran de origen mexicano contra 20 por 100 de procedencia española, francesa, alemana y genovesa. Ciertamente, los productos muestran la formación de una red de comunicaciones comerciales, generando en el interior de la Nueva España una movilización humana encargada de producir, transportar y vender las mercancías enviadas de «gobierno a gobierno», lo cual se liga con el fortalecimiento y mantenimiento de la presencia hispana en Filipinas, porque es posible observar los esfuerzos de una administración colonial para mantener a otra allende del mar, lo prueba el hecho de que: a) fue una conquista tardía; b) el estado de guerra constante hispano-holandés e his-

${ }^{31}$ AGN, AHH, 6, exp. 42, «El valor de 4.000 varas de paño para el despacho de las naos de Filipinas», México, 27-2-1635.

${ }^{32}$ AHINAH, Colección G. de Orozco, 56, p. 26, «Memorial a nombre de las yslas Filipinas contra un diputado sobre el comercio», en Comercio de Filipinas. Colección de siete piezas manuscritas relativas al comercio de Filipinas.

${ }^{33}$ Romano (1993), p. 138.

34 Romano (1993), p. 138. 
pano-mahometano; c) la defensa del archipiélago; d) la dificultad de poblamiento novohispano y peninsular, y $e$ ) la lejanía con respecto a Nueva España.

\section{D) Valores}

Confieso que los datos relativos a los valores de los productos embarcados en el galeón de la Carrera de Poniente no aportan mucho, pues hasta el momento es imposible ofrecer porcentajes, ponderaciones, fluctuaciones o series. A pesar de ello, me gustaría insistir sobre el hecho de que los valores, obligatoriamente, me llevan a discutir lo relacionado con los «asientos» novohispanos del galeón. De 1626 a 1654 solamente he identificado tres:

1) Las drogas y las boticas. Los boticarios Cristóbal Flores y Urbán Martínez, vecinos de la ciudad de México, surtieron los medicamentos para los enfermos del galeón, los hospitales de las islas y los presidios españoles en Filipinas. El asiento inició el 16 de febrero de 1635, no obstante la contratación finalizaba cada nueve años, así sucedió en enero de 1645 y en enero de 1653. Entre las condiciones del concierto resalta el compromiso de suministrar el embalaje de cada «remedio», y responsabilizarse de que los protomédicos inspeccionaran las medicinas en la Almoneda de México, dando razón del buen estado de las boticas ${ }^{35}$.

2) La pólvora y el salitre refino. El capitán Francisco de Ortega celebró contrato con la Corona para surtir salitre y pólvora para Filipinas. En lo concerniente al asiento y la renovación del mismo, las fuentes son limitadas y no aportan datos contundentes, sugieren, no obstante, que la participación de Ortega duró veintidós años: de 1641 a $1663^{36}$.

3) El bizcocho y las leguminosas. En 1644 los «bizcocheros» Clemente Patiño, Alonso de Loria y Francisco Mateos, vecinos de Los Ángeles,

${ }^{35} \mathrm{AGN}, \mathrm{AHH}, 600$, exp. 4, foja 1, «El valor de las medicinas y drogas para las Islas Filipinas», México, 7-3-1636. AGN, AHH, 600, exp. 4, foja 3, «El valor de las medicinas y drogas para remitir a las Islas Filipinas», México, 16-1-1635. AGN, AHH, 6, exp. 460, «Boticarios encargados de la provisión de drogas para Filipinas», México, 1654. AGN, AHH, 600 , exp. 4, foja 2 , «El valor de las medicinas, drogas y vasijas de los medicamentos para remitir a Filipinas y a los enfermos de las naos», México, 6-3-1636. AGN, AHH, 600, exp. 4, foja 2, «El valor de las drogas y medicinas para remitir a las Islas Filipinas», México, 7-3-1636.

${ }_{36} \mathrm{AGN}, \mathrm{AHH}, 6$, exp. 103, «Índices de reales títulos correspondientes al despacho de la nao de 1641», México, 1641. AGN, AHH, 600, exp. 7, foja 1, «El valor de 500 quintales de pólvora para remitir a Filipinas», México. AGN, AHH, 600, exp. 7, foja 2, «El capitán Francisco de Ortega, asentista de pólvora», México, 12-3-1663. 
contrataron con el virrey el asiento del bizcocho para la nao de Filipinas, aunque su participación data de 1635 . El apelativo «bizcochero» implicaba la provisión de la galleta de mar, frijol, haba, lenteja, pipas y queso. En el contrato se registraba el nombre de los responsables del «asiento», el compromiso de trajinar los productos hasta el puerto de Acapulco, los efectos y víveres que debían suministrarse, y el valor que la Corona fijaba a cada vivere, sin embargo las cantidades no eran señaladas, pues los oficiales reales de Acapulco esperaban la llegada de los barcos, «las cartas del gobernador, la gente que se pidiere y la que dichas naos trujeren» ${ }^{37}$.

Definitivamente, por medio del «asiento» lograba asegurarse un aprovisionamiento constante, seguro, de «buena calidad» y con un valor estable, lo cual implicaba, aunque sea teóricamente, la estabilidad de éstos. Paradójicamente, los ejemplos que se presentan en el apéndice III sólo pretenden ser un «botón de muestra», cuya finalidad consiste en ilustrar el hecho, no comprobarlo en su conjunto. Pero todavía quedan por examinar los valores relacionados con los productos que, aparentemente, no conformaban un «asiento». Debo confesar que el listado del apéndice IV se reduce a una simple compilación, por lo tanto la prudencia me obliga a ser parco en este renglón tan delicado. No obstante, la consecución de una paciente y tenaz búsqueda en archivos mexicanos espero que arroje resultados más alentadores. En ese sentido, los valores del resto de los «efectos y víveres» sólo deben tomarse como ejemplos ilustrativos que permitan echar un primer vistazo producto por producto. Valgan, pues, estos argumentos para suscitar la crítica positiva.

\section{E) Las cargas del galeón: el uso}

En principio, es necesario manejar el argumento de Pierre Chaunu basado en la idea de que «Filipinas ha sido mucho más colonia del continente americano, de una Nueva España ya colonizada, que colonia de Europa» ${ }^{38}$. Por otra parte, se confirma el hecho relativo a los preparativos realizados y a la movilización humana generados en el interior de la Nueva España, antes de que el galeón atracara definitivamente en el puerto de Acapulco, pues cuando el barco realizaba el cabotaje próximo al puerto

${ }^{37}$ AGN, AHH, 472, exp. 61, «Compra de bastimentos para la nao que viene este presente año de las Islas de Poniente», México, 23-11-1644.

${ }^{36}$ Chaunu (1976), p. 25. 
de Barra de Navidad se enviaba una carta al virrey ${ }^{39}$, cuyo objetivo era anunciar su presencia en la cercanía del litoral novohispano, a fin de iniciar los preparativos para su compostura y todo lo relacionado con el viaje de retorno. En ese sentido, la administración novohispana pretendía cumplir con las peticiones apuntadas en los memoriales del gobernador general.

Carmen Yuste ha denominado a las mercancías del tráfico Acapulco-Manila como las «exportaciones». Según la autora, de 1590 a 1785 , destacan dos grupos: primero, los efectos comprados en la feria de Acapulco como la grana cochinilla y el jabón; y segundo, un grupo de mercancías enviadas por parte de la administración virreinal al gobierno filipino, tales como los sombreros, el vino, el hilo de Campeche y los artículos de herrería ${ }^{40}$. No obstante, estas categorías centran su atención en un período muy amplio. Yo sólo me concentro en la primera mitad del siglo XVII, por ello mis resultados son diferentes.

Las razones para afirmar que los intercambios Acapulco-Manila fueron especialmente importantes se apoyan en que el origen de las mercancías me sugiere una dependencia arraigada de productos novohispanos y europeos en las Filipinas españolas, pues los productos no traspasaban los umbrales de las islas, ya que sólo cubrían las necesidades de la administración española avecindada en ellas, asimismo eran productos que el mercado chino y la población local isleña no podían aportar.

Las cargazones pueden clasificarse en cuatro tipos principales:

1. Abasto para la nao. Este abasto se divide en dos grupos. Primero, las materias primas y de reparación como la lona y las agujas calzadas de acero, imprescindibles para remendar el velamen del barco ${ }^{41}$; el cable cáñamo y el hilo galladero, para coser las velas, debían ser nuevos, ya que, en más de una ocasión, se proveían jarcias de las empleadas en los galeones de la Carrera de Indias; la cera embarcada en forma de velas se empleaba en los faroles tan indispensables para iluminar al galeón cuando viajaba de noche; las tablas de pino estibadas debían medir «más de siete cuartas de largo y tercio de ancho» ${ }^{42}$, pues con ellas se resarcían los daños

${ }^{39}$ Quintana (1971), pp. 35-44

40 Yuste López (1984), pp. 26 y 27

${ }^{41}$ AGN $, A H H, 6$, exp. 55, «EI valor de 12 mil agujas de acero para remitir a Filipinas», México, 8-2-1641. AGN, AHH, 6, exp. 435, «Géneros que se dieron para el despacho de las naos a Filipinas», México, 27-4-1628. AGN, AHH, 6, exp. 430, «Géneros que se remataron para el despacho de la nao a Filipinas», México, 26-3-1628. AGN, AHH, 6, exp. 201, «Indice de reales títulos correspondientes al despacho de las naos a Filipinas de 1636», México, 1636. AGN, AHH, 6, exp. 103, «Indices correspondientes al despacho de las naos de Filipinas en $1641 »$, México, 1641

${ }^{42}$ AGN, AHH, 6, exp. 207, «El valor de las tablas que se dieron en Acapulco para las naos de Filipinas», Acapulco, 15-4-1636. 
ocasionados en el casco de la nave, la cubierta, los pañoles, los camarotes de los capitanes de infantería, la carena y el calafateado ${ }^{43}$; la herrería para el barco estuvo constituida por el material de carpintería, empleado por los artesanos encargados de realizar las composturas de la nave durante la travesía (clavos, barrenas, gubias, martillos de carpintería, martillos de bomba, martillos de libera, azuelas, escoplos, pez, tachuelas, estoperoles), y por los géneros de lata (linternas, faroles, embudos, alcuzas, hojas de lata chicas y grandes) ${ }^{44}$. Es de destacar que estos materiales no retornaban de Manila a Nueva España, prueba de ello son las peticiones en los memoriales del capitán general del archipiélago, suplicando al virrey que provea el material, pues en Filipinas escaseaba el hierro. El segundo grupo estaba constituido por los pertrechos militares dispuestos para la defensa del barco en momento de ataque «pirático». En efecto, «las armas y lo demás es muy necesario para la guarnición de la dicha nao capitana para la gente y soldados que fueren en ella» ${ }^{45}$. La insistencia en la remisión de este material tiene su precedente en la captura del galeón Santa Ana en 1587 por $\mathrm{T}$. Cavendish, pues en aquel momento, el navío no contaba con pertrechos modernos. Ahora entre los cargamentos figuraba: cobre, fierro, pólvora, hachas, «cueros curtidos para bombas que llaman cerradas», moldes para hacer balas, los arcabuces y los mosquetes de cuerda ${ }^{46}$.

2. Abasto para la tripulación. Por tripulación debe entenderse al conjunto de individuos que realizaban el tornaviaje de Acapulco a Filipinas, entre ellos figuraban la oficialidad, soldados, forzados, marinería y pasajeros de alto rango. Cuatro tipos de matalotajes viajaban en el barco: primero, los víveres castellanos como el aceite, harina, vinagre y vino; segundo, la dieta seca: almendra, avellana, bizcocho, haba, garbanzo, jamón, lenteja, pasa, pescado seco y tocino; tercero, los dulces, almíbares y natillas, de

${ }^{43}$ AGN, AHH, 6, exp. 408, «El valor de tablas y plomo en pan para las naos», México, 27-1-1627. AGN, AHH, 6, exp. 438, «Remate de las tablas de pino para la nao de Filipinas», Acapulco, 30-4.de 1628. AGN, AHH, 6, exp. 211, «El valor de 1.100 tablas de pino ordinarias para la nao de Filipinas», Acapulco, 29-4-1639.

${ }_{44}$ AGN, AHH, 6, exp. 453, «Géneros para Filipinas y barcos del real servicio de Acapulco», México, 28-4-1628. AGN, AHH, 6, exp. 429, «Géneros de herrería para la achata y barcos del real servicio de Acapulco», México, 2-3-1628. AGN, AHH, 6, exp. 495, «El valor de los géneros de herrería rematados en la real almoneda de México para Filipinas», México, 26-2-1636.

${ }^{45}$ AGN, AHH, 6, exp. 62, «Memorias de los géneros que se han de traer de la Nueva España en las naos que se despachan a ella este año de 1639», México, 1639.

46 AGN, AHH, 6, exp. 48, «Pertrechos y bastimentos para la nao capitana San Juan Bautista que ha de volver a las Islas Filipinas en 1641», México, 17-1-1641. AGN, AHH, 6, exp. 62, «Memorias de los géneros que se han de traer de la Nueva España en las naos que se despachan a ella este año de 1639», Manila, 1639. 
membrillo y de durazno; cuarto, una serie de «víveres diversos», queso de cabra y oveja, agua y legumbres. Un grupo aparte estaba conformado por las drogas y boticas «para los enfermos de las dichas naos» ${ }^{47}$. En ese sentido, algunos alimentos debían cumplir con un estricto control de calidad como la galleta de mar, pan ácimo cocido dos veces, con la que se acompañaba la comida, y se dividía en dos clases: el bizcocho bazo, consumido en el puerto y galeón por los «sirvientes» de Acapulco, los forzados y la baja marinería; y el bizcocho blanco, destinado a los pasajeros de alto rango y los enfermos, así como por el resto del cuerpo marinero cuando llegaba a escasear el pan bazo. El jamón y el tocino debían tener un añejamiento de ocho meses. Pero ¿a qué respondían estas exigencias? Los alimentos debían soportar la humedad del mar, por ello eran frutos secos y comida salada. Por otro lado, este abasto sugiere que los forzados, los soldados, la baja y alta marinería y los pasajeros de alto rango consumían los mismos alimentos durante el viaje de retorno a Filipinas, incluso el vino. Es de destacar que las provisiones escaseaban con regularidad, por lo que el viaje resultaba poco placentero cuando los alimentos se descomponían y la dieta se transformaba en algo nauseabundo: frijoles, habas, avellanas y pasas con gorgojos, pescado seco salado y jamones en mal estado, que no obstante debían consumirse. El agua también se corrompía, convirtiéndose en hedionda, en consecuencia, no podía beberse, e iniciaba el «robo hormiga» de vino. Esto explica las continuas quejas por parte de los oficiales reales de Manila, pues corrientemente subrayaban el buen cuidado de los toneles de vino, que solían llegar alterados e incompletos ${ }^{48}$.

3. Abasto para las islas. Se refiere al grupo de efectos remitidos por parte del virrey de la Nueva España al gobernador general de las islas, destinados a subvenir las necesidades de la población civil, militar y religiosa avecindada en Filipinas ${ }^{49}$. No eran productos enviados a los indígenas malayos, pues durante el período aquí estudiado, el archipiélago contaba con una agricultura explotada por ellos, cuya alimentación estaba constituida por arroz, pescado, carne de carabao, carne de cerdo, aceite de coco, sal, plátanos, camotes, harina de palma y bebidas como la tuba y el pangasi. Este abasto se divide en seis grupos: víveres castellanos, tejidos, libros y papel, materiales para curación, pertrechos navales y pertrechos

$47 \mathrm{AGN}, \mathrm{AHH}, 6$, exp. 430, «Géneros que se rematan para el despacho de la nao a Filipinas», México, 26-3-1628.

${ }^{48}$ Ver nota 52.

49 Este abasto se dirigía exclusivamente a la comunidad avecindada intramuros de Manila. 
militares. Entre los víveres destaca el aceite, harina, sebo de cerdo, vinagre $\mathrm{y}$ vino. Con «el harina de Castilla para celebrar» ${ }^{50}$ se elaboraban las hostias ofrecidas en las ceremonias religiosas, mientras que el vino se destinaba «para las misas que se diesen» ${ }^{51}$, ambos eran necesarios para el impacto religioso, porque consumidos en las iglesias constituían uno de los elementos de convivencia entre la población de origen europeo y malayo, legitimando el orden cristiano insular. Por otra parte, los tejidos más comunes eran frazadas, jerguetas, paños, sayales, fieltros para sombreros y sombreros. Con el sayal se confeccionaban los hábitos de los frailes, también servía como asiento y atuendo a los forzados de las galeras de Filipinas; los sombreros encontraron un gran mercado entre los comerciantes «manilos» o «chinos» y la administración española insular; las frazadas y las jerguetas de colores cubrían las necesidades de los «hospitales de Cavite y Manila», de los conventos que alojaban a los enfermos ${ }^{52}$ y del Real Colegio de Santa Potenciana ${ }^{53}$. Pero en el archipiélago, los indígenas confeccionaban sus vestimentas con el algodón cultivado en las islas. Teñían las telas de variados colores, pues disponían de diferentes y abundantes sustancias tintóreas como el índigo, la bonga, el sibucao y otras raíces. En el siglo Xvi los residentes europeos y un gran número de indígenas vestían de «ropa de China», como genéricamente se designaba a los tejidos importados de China: seda y algodón, vendidos por los sangleyes. En efecto, señala Díaz-Trechuelo, que la sayasaya fue uno de los tejidos más usados en Filipinas, porque el módico precio resultaba atractivo para los habitantes de escasos recursos ${ }^{54}$. Y aunque la industria textil trató de fomentarse

${ }^{50}$ AGN, AHH, 6, exp. 48, «Pertrechos y bastimentos para la nao capitana San Juan Bautista que ha de volver a las Islas en 1641», México, 17-1-1641. AGN, AHH, 600, exp. 302, «Harina para remitir al puerto de Acapulco», Puebla, 19-12-1652.

51 AGN, AHH, 600, exp. 69, «Géneros que se remitieron en la nao que pasó a las Islas Filipinas en 1639», Acapulco, 8-4-1639. AGN, AHH, 6, exp. 199, «El valor de 351 arrobas de vino para remitir a Filipinas», México, 1635. AGN, AHH, 6, exp. 169, «El valor de 153 arrobas y 24 cuartillos de vino para remitir a los oficiales reales de Manila», Acapulco, 1635. AGN, AHH, 6, exp. 193, «Mandamiento para la paga de 244 arrobas y 24 cuartillos de vino que se remitió a Filipinas», Acapulco, 1635. AGN, AHH, 6, exp. 334, «El valor de 12 pipas de vino», México, 10-3-1637. AGN, AHH, «El valor de 48 pipas de vino de Castilla para Filipinas», México, 1640, Leg. 6-334. AGN, AHH, 6, exp. 335, «El valor de 48 pipas de vino de Castilla para Filipinas», México, 15-2-1640.

52 AGN, AHH, 6, exp. 48, «Pertrechos y bastimentos para la nao capitana San Juan Bautista que a de volver a las Islas en 1641», México, 17-1-1641. AGN, AHH, 6, exp. 62, «Memorias de los géneros que se han de traer de la Nueva España en las naos que se despachan a ella este año de 1638», Manila, 30-7-1638. AGN, AHH, 6, exp. 69, «Géneros que se remitieron en la nao que pasó a las Islas en 1639», Acapulco, 8-4-1639.

${ }^{53}$ Sales Colín (1995), pp. 115-124.

${ }^{54}$ Díaz-Trechuelo (1980), pp. 134, 135 y 144. 
hasta la segunda mitad del siglo XVIII, el consumo local de telas se basó en el algodón cultivado en Ilocos y en Ilo-Ilo, que también era empleado para diseñar las velas de los galeones que partían a Nueva España. Otros tejidos confeccionados y usados por la población malaya eran fabricados con las fibras de piña (pina) y de bananos (jusi), con las que hoy se hace el traje nacional filipino. Lo que atañe a la papelería también resultó de suma importancia para una maquinaria administrativa insular bastante activa, por ejemplo, los libros de contabilidad llegaban a la caja de Manila, los libros de papel de marca mayor se remitían para la contaduría de Filipinas, y el papel en resma era utilizado en las diferentes tareas de la administración isleña ${ }^{55}$. El material para curación como las agujas para heridos, jeringas, ventosas, drogas y boticas se destinaban a los hospitales y los presidios de las islas: Iligan, Tandang y Zamboanga ${ }^{56}$. Las riquezas filipinas no eran totalmente conocidas por los europeos. Así sucedía con el salitre en Sambales y el hierro en Parapanay, cuya explotación sólo se inició a finales del siglo $\mathrm{xvm}{ }^{57}$, por lo tanto, había escasez de estos materiales, así que la demanda se cubría importando desde México algunas cantidades de salitre, las hojas de lata y los aros de fierro para la «fundición de Manilas ${ }^{58}$, el plomo usado para soldar, y el hierro ${ }^{59}$, también importado de China, resultaban imprescindibles para la arquitectura naval desarrollada en las islas. Además, de México llegaba lona para fabricar las velas de los galeones recién construidos en el archipiélago, y agujas para coserlas. En definitiva, la madera era uno de los pocos recursos filipinos materiales disponibles en abundancia. Los pertrechos militares se destinaban para la defensa de las islas, en la guerra hispano-holandesa del norte, y contra los malayo-mahometanos del sur. Por esas razones, desde México se enviaban mosquetes, arcabuces, «moldes para hacer balas», espadas, machetes, salitre y pólvora.

55 AGN, AHH, 6, exp. 206, «Índices de reales títulos correspondientes al despacho de las naos a Filipinas en el año de 1634», México, 1634. AGN, AHH, 6, exp. 366, «El remate del papel en resma para Filipinas», México, 20-3-1636. AGN, AHH, 6, exp. 56, «El valor de los libros y papel de marca mayor para el gobernador de Filipinas», México, 1642.

${ }^{56} \mathrm{AGN}, \mathrm{AHH}, 600$, exp. 1-7, «El valor de las drogas y las boticas para remitir a las Islas», México, 1634-1650. AGN, AHH, 472, exp. 68, «Medicinas para los enfermos del viaje de la nao de Filipinas», México, 13-3-1646.

${ }_{57}$ A mediados del siglo xvil se descubrió hierro en las minas de Paracali y Mambulao. La de Paracali empezó a ser explotada, pero no producía lo suficiente para que fuera rentable, y fue abandonada hacia 1669, permaneciendo inactiva hasta 1696.

58 AGN, AHH, 6, exp. 62, «Memoria de los géneros que se han de traer de la Nueva España en las naos que se despachan este año de 1639», México, 1639.

59 Prieto Lucena (1984), p. 44. 
4. Abasto para las órdenes religiosas. Se despachaba, especialmente, a los Franciscanos de la provincia de San Gregorio y los Dominicos de la provincia del Santo Rosario ${ }^{60}$. En ese sentido, el Real Patronato se ejercía por medio del Consejo de Indias y las Audiencias. Por ello, en Filipinas, el Estado español proveía de todo lo necesario al clero insular, otorgaba dinero para su manutención, remitía géneros como el arroz, aceite de coco, cera y vino destinados a la alimentación o culto ${ }^{61}$. A esta lista se agregaban: conservas, sayal pardo, boticas con aceite de Castilla, libros, sacos con lana, haba y garbanzo. Evidentemente, no pretendo finalizar este artículo aportando conclusiones perentorias, pues la cuestión recién se plantea. Más bien quisiera apuntar algunas consideraciones que permitan en un futuro no muy lejano proseguir con el debate aquí planteado. En suma, se comprueba que: a) la visión tradicional del comercio transpacífico visto exclusivamente desde Filipinas reduce la óptica de los intercambios Acapulco-Manila, ya que no sólo se exportaba plata. Los territorios mexicanos de la Nueva España ejercieron el protagonismo en la relación con Asia enviando productos de «gobierno a gobierno», logrando el mantenimiento y robustecimiento de la presencia española en Filipinas; $b$ ) la repetición acrítica basada en la idea de que solamente se remitía plata de América a Asia ha creado una aceptación generalizada, sin realizar previamente la hechura de tipologías de cargamentos remitidos de Acapulco a Manila; $c$ ) resulta bastante prematuro calcular numéricamente el total de los galeones que realizaban la travesía transpacífica, por lo tanto habrá que realizar estudios del movimiento portuario de Acapulco para contar con números más certeros, a fin profundizar en lo que respecta al nombre de los galeones que zarpaban cargados con los productos demandados por el gobernador de Filipinas, para establecer, con certidumbre, los momentos en que la administración insular realizaba compras perentorias con otras embarcaciones europeas no españolas; $d$ ) frente a la ausencia de series de valores y volúmenes, de las mercancías europeas y mexicanas, deberá trabajarse, momentáneamente, con cifras ilustrativas que permitan, más adelante, diferenciar el consumo de los bajeles implicados en el tráfico marítimo con respecto al consumo de la administración insular; $e$ ) el análisis del comer-

60 AGN, AHH, 472, exp. 60, «El flete de dos pipas de vino, medicinas y demás géneros enviados a los religiosos de San Francisco», Acapulco, 1-4-1646. AGN, AHH, 600, exp. 69, «Religiosos descalzos de San Francisco de la provincia de San Gregorio en las Islas Filipinas. Mandamiento para la paga de lo que tienen señalado en cada año», México, 1628-1664. AGN, AHH, 600, exp. 68, «Religiosos de Santo Domingo de la provincia del Santo Rosario. Mandamiento para la paga de 1.200 pesos que se tienen señalados en cada año", México, 1628-1664.

${ }^{61}$ García de los Arcos (1988), pp. 47, 50 y 121. 
cio transpacífico será completo cuando se tengan datos relativos a los intercambios Manila-Acapulco, lo que redundará en el conocimiento, la importancia y la función de Filipinas dentro del imperio, evitando subrayar de forma exclusiva la relevancia de Nueva España, pues se ahondaría en el comercio en ambas direcciones; $f$ finalmente, para no caer en protagonismos ridículos que sobrevaloren erróneamente la participación de Acapulco y Manila dentro del comercio exterior de Nueva España con Asia, tendrán que matizarse las justas dimensiones históricas del negocio transpacífico recurriendo a otros indicadores, que no se limiten exclusivamente al almojarifazgo, permitiendo el estudio de las regiones internas y externas estimuladas por el comercio entre España-Nueva España-Filipinas.

\section{APÉNDICE I}

Entrada y salida de barcos del puerto de Acapulco: 1626-1654

\begin{tabular}{|c|c|c|c|}
\hline$A \tilde{n} o$ & Procedencia & Nombres & Destino \\
\hline $1626 \ldots$ & Filipinas & San Jacinto & Acapulco \\
\hline $1628 \ldots$ & Filipinas & - & Acapulco \\
\hline $1633 .$. & Filipinas & - & Acapulco \\
\hline $1634 \ldots$ & Filipinas & - & Acapulco \\
\hline $1635 \ldots$ & Cavite & Nuestra Señora de la Concepción & Acapulco \\
\hline $1635 .$. & Cavite & San Luis & Acapulco \\
\hline $1636 \ldots$ & Acapulco & San Nicolás & Manila \\
\hline $1637 \ldots$ & Cavite & San Juan Bautista & Acapulco \\
\hline $1637 .$. & Manila & Nuestra Señora de la Concepción & Acapulco \\
\hline $1638 \ldots$ & Manila & Nuestra Señora de la Concepción & Acapulco \\
\hline $1639 \ldots$ & Filipinas & San Ambrosio & Acapulco \\
\hline $1639 \ldots .$. & Filipinas & Nuestra Señora de la Concepción & Acapulco \\
\hline $1640 \ldots \ldots \ldots \ldots \ldots$ & Filipinas & Nuestra Señora de la Concepción & Acapulco \\
\hline $1641 \ldots \ldots \ldots \ldots . . . . .$. & Filipinas & San Juan Bautista & Acapulco \\
\hline $1643 \ldots \ldots \ldots \ldots \ldots$ & Filipinas & Nuestra Señora del Rosario & Acapulco \\
\hline $1644 \ldots \ldots \ldots \ldots \ldots$ & Filipinas & - & - \\
\hline $1645 \ldots \ldots \ldots \ldots \ldots$ & Filipinas & Nuestra Señora del Rosario & Acapulco \\
\hline $1645 \ldots \ldots \ldots \ldots \ldots$ & Filipinas & Nuestra Señora del Encarnación & Acapulco \\
\hline $1646 \ldots \ldots \ldots \ldots \ldots$ & Filipinas & San Luis Rey de Francia & Acapulco \\
\hline $1649 \ldots \ldots \ldots \ldots \ldots$ & Filipinas & Nuestra Señora de la Encarnación & Acapulco \\
\hline $1650 \ldots$. & Filipinas & Nuestra Señora de la Guía & Acapulco \\
\hline $1652 \ldots$ & Filipinas & San Francisco Javier & Acapulco \\
\hline $1652 \ldots \ldots \ldots \ldots \ldots$ & Filipinas & Nuestra Señora de la Guía & Acapulco \\
\hline $1653 \ldots \ldots \ldots \ldots \ldots$ & Filipinas & San Diego & Acapulco \\
\hline $1654 \ldots .$. & Filipinas & San Diego & Acapulco \\
\hline
\end{tabular}

FUENTE: Sales Colín (1996), pp. 116 y 117. El cuadro que ahora presento ha sido modificado, de tal manera que sólo contiene los barcos procedentes de Filipinas, sin tomar en cuenta los de Sonsonate y Callao. Además he agregado los años 1628, 1633, 1634 y 1644. 


\section{APÉNDICE II}

Cargazones de galeón de la Carrera de Poniente: 1626-1654

\begin{tabular}{|c|c|c|c|}
\hline$A \bar{n} o$ & Mercancia & Cantidad & Destino \\
\hline 1626 & $\begin{array}{l}\text { Tablas de pino } \\
\text { Tablas de pino } \\
\text { Paño } \\
\text { Pescado salado } \\
\text { Hilo galladero } \\
\text { Lona } \\
\text { Tablas de pino } \\
\text { Tablas de pino } \\
\text { Plomo en pan } \\
\text { Avellana } \\
\text { Quesos } \\
\text { Cajetas } \\
\text { Pasa } \\
\text { Almendra } \\
\text { Membrillo } \\
\text { Plomo en pan } \\
\text { Fieltros } \\
\text { Sebo de cerdo } \\
\text { Lona } \\
\text { Frazadas }\end{array}$ & $\begin{array}{l}200 \text { piezas } \\
1.400 \text { piezas } \\
3.000 \text { varas } \\
5.466 \text { arrobas } \\
100 \text { libras } \\
2.000 \text { varas } \\
1.300 \text { piezas } \\
100 \text { piezas } \\
6 \text { quintales } \\
2 \text { quintales } \\
1.400 \text { piezas } \\
52 \text { arrobas } \\
8 \text { arrobas } \\
28 \text { arrobas } \\
150 \text { cascos } \\
- \\
2.000 \text { piezas } \\
1.000 \text { arrobas } \\
300 \text { piezas } \\
300 \text { piezas }\end{array}$ & $\begin{array}{c}\mathrm{G} \\
\mathrm{G} \\
\mathrm{I} \\
\mathrm{T}-\mathrm{S} \\
\mathrm{G} \\
\mathrm{G} \\
\mathrm{G} \\
\mathrm{G} \\
\mathrm{G} \\
\mathrm{G} \\
\mathrm{T} \\
\mathrm{T} \\
\mathrm{T} \\
\mathrm{T} \\
\mathrm{T} \\
\mathrm{I} \\
\mathrm{I} \\
\mathrm{I} \\
\mathrm{I} \\
\mathrm{I}\end{array}$ \\
\hline 1628 & $\begin{array}{l}\text { Garbanzo } \\
\text { Herrería } \\
\text { Pipas } \\
\text { Aceite } \\
\text { Estoperoles } \\
\text { Jerguetas } \\
\text { Fieltros } \\
\text { Sombreros } \\
\text { Plomo tirado } \\
\text { Pipa } \\
\text { Lenteja }\end{array}$ & $\begin{array}{l}12 \text { fanegas } \\
\text { Varios } \\
1.050 \text { piezas } \\
250 \text { arrobas } \\
25.000 \\
12.000 \\
2.000 \\
8 \text { docenas } \\
56 \text { quintales } \\
990 \text { piezas } \\
57 \text { fanegas }\end{array}$ & $\begin{array}{c}I \\
P \\
\text { G-I } \\
I-T \\
\text { G-P } \\
I \\
I \\
I \\
\text { G-I } \\
\text { G-I } \\
\text { O-I }\end{array}$ \\
\hline 1633 & Vinagre blanco & 50 arrobas & $M \cdot S$ \\
\hline 1634 & $\begin{array}{l}\text { Plomo tirado } \\
\text { Espadas } \\
\text { Libros } \\
\text { Frazadas } \\
\text { Medicinas } \\
\text { Pescado seco }\end{array}$ & $\begin{array}{l}- \\
\overline{4} \\
\overline{\text { Varias }} \\
413 \text { arrobas }\end{array}$ & $\begin{array}{c}\text { I } \\
\text { I } \\
\text { I } \\
\text { I } \\
\text { I } \\
M-T-S\end{array}$ \\
\hline
\end{tabular}




\begin{tabular}{|c|c|c|c|}
\hline$A \bar{n} o$ & Mercancia & Cantidad & Destino \\
\hline & Azufre & - & $\mathrm{G}$ \\
\hline & Cobre & 一 & G \\
\hline \multirow[t]{4}{*}{1635} & Paño & 4.000 varas & I \\
\hline & Vino & 244 arrobas & I \\
\hline & Vino & 153 arrobas & I \\
\hline & Vino & 351 arrobas & I \\
\hline \multirow[t]{18}{*}{1636} & Géneros de lata & Varios & G \\
\hline & Tablas de pino & 1.000 piezas & G \\
\hline & Tablas de pino & 500 piezas & $\mathrm{G}$ \\
\hline & Cera & 450 achotes & G \\
\hline & Herrería & Varios & $\mathrm{G}$ \\
\hline & Pipas & 500 piezas & $\mathrm{G}$ \\
\hline & Garbanzo & 25 fanegas & $\mathrm{T}$ \\
\hline & Paño & 1.998 varas & I \\
\hline & Papel & 200 resmas & I \\
\hline & Hojas de lata & 30 piezas & I \\
\hline & Jerguetas & 10.600 & I \\
\hline & Libros & 4 piezas & $\mathrm{I}$ \\
\hline & Garbanzo & 95 fanegas & $\mathrm{I}-\mathrm{T}$ \\
\hline & Medicinas & Varias & G-I \\
\hline & Machetes & 200 piezas & $\mathrm{G}$ \\
\hline & Lona & 1.500 varas & $\mathrm{G}$ \\
\hline & Tocino & - & $\mathrm{T}$ \\
\hline & Aceite & - & $\mathrm{T}$ \\
\hline \multirow[t]{8}{*}{1637} & Pipas & 500 piezas & $\mathrm{G}$ \\
\hline & Tocino & 500 arrobas & $\mathrm{T}$ \\
\hline & Vinagre & 300 arrobas & $\mathrm{T}$ \\
\hline & Cajetas & 32 arrobas & $\mathrm{T}$ \\
\hline & Aceite & 225 arrobas & $T$ \\
\hline & Queso & 200 arrobas & $\mathrm{T}$ \\
\hline & Vino & 12 pipas & $\mathrm{T}$ \\
\hline & Garbanzo & 25 fanegas & $M-S$ \\
\hline \multirow[t]{8}{*}{1638} & Pipas & 519 piezas & G \\
\hline & Cera & 25 arrobas & $\mathrm{G}$ \\
\hline & Pipas & 120 piezas & G \\
\hline & Tablas de pino & 1.100 piezas & $\mathrm{G}$ \\
\hline & Tocino & 450 arrobas & $\mathrm{T}$ \\
\hline & Plomo en pan & 200 quintales & I \\
\hline & Plomo tirado & 200 quintales & 1 \\
\hline & Aceite & 155 arrobas & I \\
\hline
\end{tabular}




\begin{tabular}{|c|c|c|c|}
\hline$A \bar{n} o$ & Mercancía & Cantidad & Destino \\
\hline & $\begin{array}{l}\text { Fardos y cajones } \\
\text { Fieltros } \\
\text { Espadas } \\
\text { Agujas para velas } \\
\text { Medicinas } \\
\text { Lona } \\
\text { Haba }\end{array}$ & $\begin{array}{l}\text { Varios } \\
1.000 \\
200 \text { piezas } \\
12.000 \\
\text { Varias } \\
80 \text { varas } \\
220 \text { fanegas }\end{array}$ & $\begin{array}{c}\text { I } \\
\text { I } \\
\text { I } \\
I \\
\text { G-I } \\
\text { G-I } \\
T\end{array}$ \\
\hline 1640 & $\begin{array}{l}\text { Cera } \\
\text { Tocino } \\
\text { Queso } \\
\text { Avellana } \\
\text { Lenteja } \\
\text { Plomo tirado } \\
\text { Espadas } \\
\text { Hojas de lata } \\
\text { Fieltros } \\
\text { Sebo de cerdo } \\
\text { Cajones para sebo } \\
\text { Vino } \\
\text { Vino } \\
\text { Fardos y cajones } \\
\text { Aceite }\end{array}$ & $\begin{array}{l}12 \text { arrobas } \\
250 \text { arrobas } \\
134 \text { arrobas } \\
2 \text { quintales } \\
40 \text { fanegas } \\
200 \text { quintales } \\
600 \text { piezas } \\
2.000 \text { piezas } \\
2.000 \text { piezas } \\
500 \text { arrobas } \\
85 \text { piezas } \\
48 \text { pipas } \\
48 \text { pipas } \\
\text { Varios } \\
180 \text { arrobas }\end{array}$ & $\begin{array}{c}\mathrm{G} \\
\mathrm{T} \\
\mathrm{T} \\
\mathrm{T} \\
\mathrm{T} \\
\mathrm{I} \\
\mathrm{I} \\
\mathrm{I} \\
\mathrm{I} \\
\mathrm{I} \\
\mathrm{I} \\
\mathrm{I} \\
\mathrm{I} \\
\mathrm{I} \\
\mathrm{P}-\mathrm{T}\end{array}$ \\
\hline 1641 & $\begin{array}{l}\text { Lona } \\
\text { Plomo tirado } \\
\text { Plomo tirado } \\
\text { Libros } \\
\text { Papel } \\
\text { Hojas de lata } \\
\text { Tachuelas } \\
\text { Pólvora } \\
\text { Agujas para coser } \\
\text { Velas } \\
\text { Medicinas }\end{array}$ & $\begin{array}{l}10 \text { varas } \\
200 \text { quintales } \\
28 \text { quintales } \\
4 \text { piezas } \\
80 \text { resmas } \\
20.000 \text { piezas } \\
24.000 \text { piezas } \\
20 \text { quintales } \\
12.000 \\
- \\
\text { Varias }\end{array}$ & $\begin{array}{l}\text { G } \\
\text { I } \\
\text { I } \\
\text { I } \\
I \\
I \\
I \\
\text { G-I } \\
\text { G-I } \\
-\end{array}$ \\
\hline 1644 & $\begin{array}{l}\text { Haba } \\
\text { Garbanzo } \\
\text { Queso } \\
\text { Bizcocho }\end{array}$ & $\frac{-}{-}$ & $\begin{array}{c}\mathrm{T} \\
\mathrm{T} \\
\mathrm{T} \\
\mathrm{M}-\mathrm{S}-\mathrm{T}\end{array}$ \\
\hline 1645 & $\begin{array}{l}\text { Pipas } \\
\text { Queso } \\
\text { Bizcocho }\end{array}$ & $\begin{array}{l}55 \text { piezas } \\
96 \text { quintales } \\
30 \text { quintales }\end{array}$ & $\begin{array}{l}\mathrm{G} \\
\mathrm{T} \\
\mathrm{T}\end{array}$ \\
\hline
\end{tabular}




\begin{tabular}{lllc}
\hline & \multicolumn{1}{c}{ Mero } & \multicolumn{1}{c}{ Cantidad } & Destino \\
\hline & Haba & 552 fanegas & T-S \\
& Frijol & 80 fanegas & T-S \\
& Garbanzo & 48 fanegas & T-S \\
& Lenteja & 30 fanegas & T-S \\
& Bizcocho & 1.101 quintales & M-S \\
& Bizcocho & 44 quintales & M-S \\
1646 & Vino & 2 pipas & I \\
& Pólvora & 500 quintales & I \\
& Fardos y cajones & Varios & I \\
& Medicinas & Varias & G-I \\
1650 & Pólvora & 500 quintales & I \\
& Salitre & 40 quintales & I \\
1652 & Harina & 2 pipas & T \\
1653 & Pescado seco & 1.328 arrobas & S-T \\
1654 & Medicinas & Varias & G-I \\
1663 & Pólvora & 500 quintales & G-I \\
\hline
\end{tabular}

G: Abasto para el galeón.

T: Abasto para la tripulación y el pasaje del barco.

I: Abasto para las Islas de Poniente.

M: Raciones para la gente de mar y de guerra instalada en el puerto de Acapulco.

S: Raciones para los «sirvientes» del puerto de Acapulco.

P: Material para el real servicio del puerto de Acapulco.

FUENTE: AGN, AHH, 6, 472 y 600.

APÉNDICE III

Valores de los efectos y viveres apuntados

en los «asientos» del barco

PÓLVORA

\begin{tabular}{cc}
\hline Año & Reales plata \\
\hline $1646 \ldots \ldots \ldots \ldots \ldots \ldots \ldots \ldots \ldots \ldots \ldots \ldots \ldots \ldots \ldots \ldots \ldots \ldots \ldots \ldots \ldots \ldots \ldots \ldots \ldots \ldots \ldots \ldots \ldots \ldots$ & 4 por libra \\
$1650 \ldots \ldots \ldots \ldots \ldots \ldots$ & 4 por libra \\
\hline
\end{tabular}

FUENTE: AGN, AHH, 6, exp. 103, y 600, exp. 7. 


\section{QUESO}

\begin{tabular}{cc}
\hline Año & Reales plata \\
\hline $1644 \ldots \ldots \ldots \ldots \ldots \ldots \ldots \ldots \ldots \ldots \ldots \ldots \ldots \ldots \ldots$ & 16 y 6 tomines por quintal \\
$1645 \ldots \ldots \ldots \ldots \ldots \ldots \ldots \ldots \ldots \ldots \ldots \ldots \ldots$ & 16 y 6 tomines por quintal \\
\hline
\end{tabular}

FUENTE: AGN, AHH, 6, exp. 330; 6, exp. 342, y 472, exp. 61.

HABA

\begin{tabular}{cc}
\hline Año & Reales plata \\
\hline $1644 \ldots \ldots \ldots \ldots \ldots \ldots \ldots \ldots \ldots \ldots \ldots \ldots \ldots \ldots \ldots \ldots \ldots \ldots \ldots \ldots \ldots \ldots \ldots$ & 7 por fanega \\
$1645 \ldots \ldots \ldots \ldots \ldots \ldots \ldots \ldots \ldots \ldots \ldots \ldots \ldots$ & 7 por fanega \\
\hline
\end{tabular}

FUENTE: AGN, AHH, 472, exp. 6.

JAMONES

\begin{tabular}{|c|c|}
\hline Año & Reales plata \\
\hline $\begin{array}{l}1637 \\
1639 \\
1640 \ldots \ldots \ldots \ldots \ldots \ldots\end{array}$ & $\begin{array}{c}3 \text { por arroba } \\
3 \text { y } 6 \text { tomines por arroba } \\
3 \text { por arroba }\end{array}$ \\
\hline
\end{tabular}

FUENTE: AGN, AHH, 6, exp. 62; 6, exp. 311, y 6, exp. 328.

BIZCOCHO

\begin{tabular}{|c|c|}
\hline$A \tilde{n} o$ & Reales plata \\
\hline 1644 & $\begin{array}{l}7 \text { por quintal } \\
7 \text { por quintal }\end{array}$ \\
\hline
\end{tabular}

Fuente: AGN, AHH, 472, exp. 61.

APÉNDICE IV

Valores de los pertrechos, bastimentos y matalotajes

SEBO

\begin{tabular}{|c|c|}
\hline Año & Reales plata \\
\hline $\begin{array}{l}1628 \\
1640\end{array}$ & $\begin{array}{c}4 \text { por arroba } \\
3 \text { y } 1 \text { tomín por arroba }\end{array}$ \\
\hline
\end{tabular}

FUENTE: AGN, AHH, G. exp. 26 y exp. 432. 


\section{GARBANZO}

\begin{tabular}{|c|c|}
\hline$A \bar{n} o$ & Reales plata \\
\hline 1636. & 10 por fanega \\
\hline ................... & 7 y 2 tomines por fanega \\
\hline 1644 & 7 por fanega \\
\hline 1645 & 3 y 4 tomines por fanega \\
\hline
\end{tabular}

FueNTE: AGN, AHH, 6, exp. 39; 6, exp. 338; 472, exp. 61.

PESCADO SECO

\begin{tabular}{cc}
\hline Año & Reales plata \\
\hline $1627 \ldots \ldots \ldots \ldots \ldots \ldots \ldots \ldots \ldots \ldots \ldots \ldots \ldots \ldots \ldots \ldots \ldots \ldots \ldots \ldots \ldots \ldots \ldots \ldots \ldots \ldots \ldots \ldots$ & 20 por fanega \\
$1653 \ldots \ldots \ldots \ldots \ldots \ldots \ldots \ldots$ & 3 por fanega \\
\hline
\end{tabular}

FUENTE: AGN, AHH, 6, exp. 552; 600, exp. 223.

PAÑO

\begin{tabular}{cc}
\hline Año & Reales plata \\
\hline $1635 \ldots \ldots \ldots \ldots \ldots \ldots \ldots \ldots \ldots \ldots \ldots \ldots \ldots \ldots \ldots \ldots \ldots \ldots \ldots \ldots \ldots \ldots \ldots$ & 9 por vara \\
$1636 \ldots \ldots \ldots \ldots \ldots \ldots \ldots \ldots \ldots \ldots \ldots \ldots \ldots$ & 4 por vara \\
\hline
\end{tabular}

FUENTE: AGN, AHH, 6, exp. 202 y exp. 426.

\section{FIELTROS PARA SOMBREROS}

\begin{tabular}{|c|c|}
\hline Año & Reales plata \\
\hline 1628 & $\begin{array}{c}12 \text { y } 4 \text { tomines por docena } \\
18 \text { por docena }\end{array}$ \\
\hline
\end{tabular}

FueNTE: AGN, AHH, 6, exp. 403 y exp. 428.

\section{PIPAS}

\begin{tabular}{|c|c|}
\hline$A \bar{n} o$ & Reales plata \\
\hline $1628 .$. & 4 y 4 tomines cada una \\
\hline $1637 \ldots .$. & 5 y 3 tomines cada una \\
\hline $1638 \ldots \ldots \ldots$ & 6 y 1 tomín cada una \\
\hline 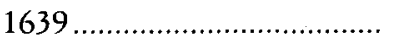 & 13 y 2 tomines cada una \\
\hline 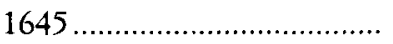 & 5 tomines cada una \\
\hline
\end{tabular}

FUENTE: AGN, AHH, 6, exp. 312, exp. 336, exp. 353 y exp. 434. 


\section{PLOMO EN PAN}

\begin{tabular}{|c|c|}
\hline$A \tilde{n} o$ & Reales plata \\
\hline 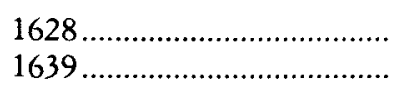 & $\begin{array}{l}9 \text { y } 4 \text { tomines por quintal } \\
5 \text { tomines por quintal }\end{array}$ \\
\hline
\end{tabular}

Fuente: AGN, AHH, 6, exp. 307 y exp. 438.

\section{PLOMO TIRADO}

\begin{tabular}{|c|c|}
\hline Año & Reales plata \\
\hline $1629 \ldots \ldots$ & 13 y 6 tomines por quintal \\
\hline 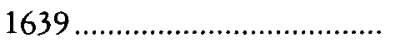 & 17 tomines por quintal \\
\hline 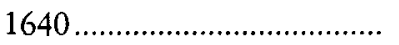 & 14 y 7 tomines por quintal \\
\hline
\end{tabular}

FUENTE: AGN, AHH, 6, exp. 307, exp. 310 y exp. 415 .

\section{CERA}

\begin{tabular}{cc}
\hline Año & Reales plata \\
\hline $1639 \ldots \ldots \ldots \ldots \ldots \ldots \ldots \ldots \ldots \ldots \ldots \ldots \ldots \ldots \ldots \ldots \ldots \ldots \ldots \ldots \ldots \ldots \ldots \ldots$ & 23 y 4 tomines por quintal \\
$1640 \ldots \ldots \ldots \ldots \ldots \ldots \ldots \ldots \ldots \ldots \ldots \ldots$ & 18 y 4 tomines por quintal \\
\hline
\end{tabular}

FUENTE: AGN, AHH, 6, exp. 306 y exp. 329.

BARRENAS

\begin{tabular}{|c|c|}
\hline Año & Reales plata \\
\hline 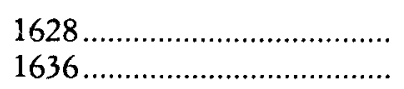 & $\begin{array}{l}9 \text { cada una } \\
4,5 \text { cada una }\end{array}$ \\
\hline
\end{tabular}

FuENTE: AGN, AHH, 6, exp. 429 y exp. 495.

ESTOPEROLES

\begin{tabular}{ll}
\hline \multicolumn{1}{c}{ Año } & Reales plata \\
\hline $1628 \ldots \ldots \ldots \ldots \ldots \ldots \ldots \ldots \ldots \ldots \ldots \ldots \ldots \ldots \ldots \ldots \ldots \ldots \ldots \ldots \ldots \ldots \ldots \ldots \ldots \ldots \ldots \ldots \ldots$ & 7 por millar \\
$1636 \ldots \ldots \ldots \ldots \ldots \ldots$ & 6 por millar \\
\hline
\end{tabular}

FUENTE: AGN, AHH, 6, exp. 435 y exp. 495. 
GUBIAS

\begin{tabular}{|c|c|}
\hline$A \bar{n} o$ & Reales plata \\
\hline 1628 & $\begin{array}{l}2 \text { cada una } \\
4,5 \text { cada una }\end{array}$ \\
\hline
\end{tabular}

FUENTE: AGN, AHH, 6, exp. 429 y exp. 495.

\section{LIBROS}

\begin{tabular}{|c|c|}
\hline$A \bar{n} o$ & Reales plata \\
\hline 1636 & $\begin{array}{l}35 \text { cada uno } \\
40 \text { cada uno }\end{array}$ \\
\hline
\end{tabular}

FUENTE: AGN, AHH, 6, exp. 56 y exp. 49.

LENTEJA

\begin{tabular}{cc}
\hline Año & Reales plata \\
\hline $1629 \ldots \ldots \ldots \ldots \ldots \ldots \ldots \ldots \ldots \ldots \ldots \ldots . . . \ldots$ & 5 y 4 tomines por quintal \\
$1645 \ldots \ldots \ldots \ldots \ldots \ldots \ldots \ldots \ldots \ldots \ldots \ldots . . \ldots$ & 13 y 4 tomines por quintal \\
\hline
\end{tabular}

FUENTE: AGN, AHH, 6, exp. 405; 472, exp. 61.

VINO

\begin{tabular}{|c|c|}
\hline Año & Reales plata \\
\hline 1635 & 345 por pipa \\
\hline 1637 & 210 por pipa \\
\hline 1640 & 300 por pipa \\
\hline
\end{tabular}

FUENTE: AGN, AHH, 6, exp. 193, exp. 196 exp. 199, exp. 335 y exp. 342.

\section{ACEITE}

\begin{tabular}{|c|c|}
\hline$A \bar{n} o$ & Reales plata \\
\hline $1628 \ldots \ldots \ldots$ & 5 y 4 tomines por arroba \\
\hline $1637 \ldots$ & 7 y 2 tomines por arroba \\
\hline 1639 & 4 y 6 tomines por arroba \\
\hline
\end{tabular}

FUENTE: AGN, AHH, 6, exp. 308, exp. 340 y exp. 435. 
CASOS MUESTRA 1. VARIOS

\begin{tabular}{|c|c|c|}
\hline Año & Género & Reales plata \\
\hline $1623 \ldots \ldots \ldots$ & Cáñamo & 30 por quintal \\
\hline 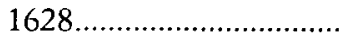 & Pasa & 7 y 6 tomines por quintal \\
\hline 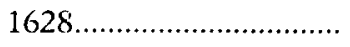 & Avellana & 25 por quintal \\
\hline …................... & Frazadas & 23 cada una \\
\hline $1628 \ldots \ldots \ldots \ldots \ldots \ldots \ldots \ldots \ldots \ldots \ldots \ldots \ldots \ldots \ldots$ & Hilo galladero & 7 por libra \\
\hline $1628 \ldots \ldots \ldots \ldots$ & Lona & 4 y 4 tomines por arrobas \\
\hline $1629 \ldots \ldots \ldots \ldots \ldots \ldots \ldots \ldots \ldots \ldots \ldots \ldots \ldots \ldots$ & Sombreros & 40 por docena \\
\hline $1629 \ldots \ldots \ldots \ldots \ldots \ldots \ldots \ldots \ldots \ldots \ldots \ldots \ldots$ & Jerguetas & 7 por vara \\
\hline 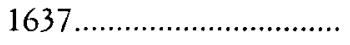 & Cajetas & 7 por arroba \\
\hline 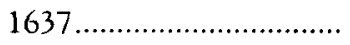 & Vinagre & 5 por arroba \\
\hline $1640 \ldots \ldots \ldots \ldots \ldots \ldots \ldots \ldots \ldots \ldots \ldots \ldots \ldots \ldots \ldots$ & Cajones & 21 cada cajón \\
\hline $1640 \ldots \ldots \ldots \ldots \ldots \ldots \ldots \ldots \ldots \ldots \ldots \ldots \ldots \ldots \ldots \ldots$ & Espadas & 8 cada una \\
\hline 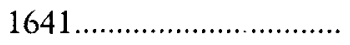 & Papel & 5 y 2 tomines por resma \\
\hline $1641 \ldots \ldots \ldots \ldots \ldots \ldots \ldots \ldots \ldots \ldots \ldots \ldots \ldots \ldots \ldots \ldots$ & Agujas para velas & 0,5 cada una \\
\hline 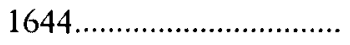 & Frijol & 8 por fanega \\
\hline 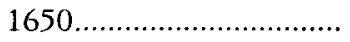 & Salitre & 20 por quintal \\
\hline
\end{tabular}

FueNTE: AGN, AHH, 6, exp. 55, exp. 56, exp. 159, exp. 327, exp. 327, exp. 332, exp. 337 , exp. 339, exp. 403, exp. 414, exp. 430, exp. 431, exp. 434, exp. 437; 472, exp. 61; 600 , exp. 7.

\section{CASOS MUESTRA 2. HERRERÍA}

\begin{tabular}{|c|c|c|}
\hline$A$ ño & Género & Reales plata \\
\hline 1628. & Clavos de costado & 2,5 reales por libra \\
\hline 1628. & Clavos de medio costado & 12,5 por libra \\
\hline $1628 \ldots$ & Clavos de escoba & 2,5 por libra \\
\hline $1628 .$. & Clavos de media escoba & 6 cada ciento \\
\hline $1628 \ldots .$. & Martillos de carpintería & 2 y 2 tomines cada uno \\
\hline $1636 \ldots \ldots \ldots$ & Candados de mástil & 7 cada uno \\
\hline $1636 \ldots \ldots \ldots$ & Hachas vizcaínas & 4 y 4 tomines cada una \\
\hline $1636 \ldots \ldots \ldots \ldots$ & Barretas & 6 tomines por libra \\
\hline $1636 \ldots \ldots \ldots \ldots$ & Azuelas & 6 cada una \\
\hline 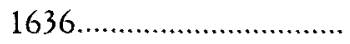 & Escoplos & 4 cada uno \\
\hline 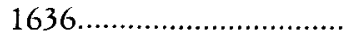 & Martillos de libera & 6 cada uno \\
\hline 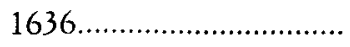 & Martillos de bomba & 2 cada uno \\
\hline $1636 \ldots \ldots \ldots \ldots \ldots \ldots \ldots \ldots \ldots \ldots \ldots \ldots \ldots \ldots \ldots \ldots \ldots$ & Tachuelas & 6 cada millar \\
\hline
\end{tabular}

FueNTE: AGN, AHH, 6, exp. 429 y exp. 495 . Herramientas empleadas para la carena y el calafateado de los navíos. 


\section{CASOS MUESTRA 3. GÉNEROS DE LATA}

\begin{tabular}{|c|c|c|}
\hline Año & Género & Reales plata \\
\hline $1636 \ldots \ldots .$. & Faroles & 85 cada uno \\
\hline (n...................... & Linternas & 85 cada uno \\
\hline 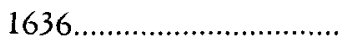 & Embudos & 4 cada uno \\
\hline 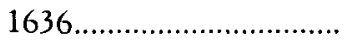 & Alcuzas & 2 cada una \\
\hline
\end{tabular}

FUENTE: AGN, AHH, 6, exp. 40.

\section{BIBLIOGRAFÍA}

Bauzon, Leslie (1981): Deficit Government. Mexico and the Philippine Situado. 1606-1804, 'Tokyo, Press Company LTD.

Chaunu, Pierre (1976): Las Filipinas y el Pacifico de los Ibéricos, siglos XVI, XVII y XVII, México, IMCE.

Díaz-Trechuelo, Lourdes (1980): «Relaciones en Oriente en la Edad Moderna. Veinte años de comercio entre Filipinas y China», en DE LA TORRE VILLAR, E. (comp.), La expansión bispanoamericana en Asia. Siglos XVl y XVII, México, FCE, pp. 134-148.

- (1984): «Las Filipinas, en su aislamiento, bajo el continuo acoso», en Historia General de España y América, t. IX-2, Madrid, Rialp, pp. 129-152.

GARCía DE los ARCOS, María Fernanda (1988): Estado y clero en las Filipinas del siglo XVIII, México, UAMI.

- (1989): «La emigración a Filipinas en el siglo XVII según los fondos del Archivo General de la Nación (México)», en Solano, F.; Rodao, S., y Togores, L. E. (eds.), El Extremo Oriente Ibérico. Metodologia, Investigaciones y Estado de la Cuestión, Madrid, ACI-CEHCSIC, pp. 231-241.

- (1993): «La batalla de la seda», en TORTOlero Villaseñor, A. (coor.), Estudios Históricos, I, México, UAMI, pp. 39-67.

- (1996): Forzados y reclutas: Los criollos novobispanos en Asia (1756-1808), México, Potrerillos Editores.

- (1997): «El comercio Manila-Acapulco: un intento de estado de la cuestión», en Yuste, C. (coor.), Comercio Maritimo Colonial. Nuevas interpretaciones y últimas fuentes, México, INAH, pp. 165-180.

GonzÁlez Claverán, Virginia (1989): «Un documento colonial sobre esclavos asiá. ticos», en Historia Mexicana, núm. 51, pp. 523-532.

- (1993): La expedición cientifica de Malaspina en Nueva España. 1789-1794, México, El Colegio de México.

Muro, Luis (1970): «Soldados de Nueva España a Filipinas (1575)», en Historia Mexicana, XIX, 4 (76), pp. 466-491.

Pérez Herrero (1989a): «El galeón de Manila. Relaciones comerciales entre el Extremo Oriente y América (El estado de la cuestión)», en SOLANO, F.; RoDAO, 
F., y Togores, L. E. (eds.) El Extremo Oriente Ibérico. Metodología, Investigaciones y el Estado de la Cuestión, Madrid, ACI-CEHCSIC, pp. 445-457.

Quintana, José Miguel (1971): «Un viaje de Filipinas a la Nueva España en el siglo XVII», en Artes de México, núm. 143, pp. 35-44.

Prieto LuCEnA, Ana María (1984): Filipinas durante el gobiemo de Manrique de Lara. 1653-1663, Sevilla, EEH.

Romano, Rugero (1993): Coyunturas opuestas. La crisis del siglo Xvll en Europa $e$ Hispanoamérica, México, El Colegio de México-Fondo de Cultura Económica.

Sales Colín, Ostwald (1994): «Las cargas del galeón de Manila», en Topodrilo, núm. 34 , pp. 30-33.

- (1995): «El colegio para mujeres de Santa Potenciana en Filipinas. Siglo XVI», en Ramos, Manuel (coord.), El Monacato Femenino en el Imperio español. Monasterios, beaterios, recogimientos y colegios, México, CEHM-CONDUMEX, pp. 115-124.

- (1996): «El movimiento portuario de Acapulco: Un intento de aproximación (1626-1654)», Revista Complutense de Historia de América, núm. 22, pp. 97-119.

- (1997a): «Un descalabro en las comunicaciones náuticas mexicano-filipinas. 1646-1648», en Consejo Cultural Filipino-MeXicano (coord.), El Galeón de Manila. Un Mar de Historias, México, JGH Editores, pp. 91-119.

- (1997b): «Una coyuntura en el comercio transpacífico. Fuentes complementarias para la visita de Pedro de Quiroga en Acapulco», en Yuste, C. (coord.), Comercio Marítimo Colonial. Nuevas Interpretaciones y Últimas Fuentes, México, INAH, pp. 127-146.

SCHURZ, William (1939): The Manila galleon, New York, Dutton and Company. Serrano Mangas, Fernando (1985): Los galeones de la Carrera de Indias. 1650-1700, Sevilla, EHH.

VALDÉS LAKOWSKY, Vera (1987): De las minas al mar. Historia de la plata mexicana en Asia: 1565-1834, México, FCE.

WIDMER, Rudolf (1990): Conquista y despertar de las costas de la Mar del Sur. 1522-1684, México, CNCA.

Yuste López, Carmen (1984): El comercio de la Nueva España con Filipinas. 1590-1785, México, INAH.

- (1987): «Francisco Ignacio de Yraeta y el comercio transpacífico», en Estudios de Historia Novobispana, vol. 9, México, UIA, pp. 189-217.

- (1991): Comerciantes mexicanos en el siglo XVII, México, IH-UNAM.

- (1992): «El galeón y la economía colonial», en El galeón del Pacífico. Acapulco-Manila, 1565-1815, México, Gobierno del Estado de Guerrero, pp. 91-111.

- (1993): «Los comerciantes de la ciudad de México en la negociación transpacífica», en LudLow, Leonor y SiLVA, Jorge (comps.), Los negocios y las ganancias. De la colonia al México moderno, México, Instituto Mora e IIH-UNAM, pp. 211-224.

- (1995): «Los precios de las mercancías asiáticas en el siglo XVII», en GARCíA Acosta, V. (coord.) Los precios de alimentos y manufacturas novohispanas, México, CIESAS, Instituto Mora e IIH-UNAM, pp. 231-264. 


\section{FUENTES}

AGN: Archivo General de la Nación, México.

AHH: Archivo Histórico de Hacienda.

GP: General de Parte.

AHINAH: Archivo Histórico del Instituto Nacional de Antropología e Historia. 